\title{
DESAIN DAN KONSTRUKSI MESIN PENYEMAI BENIH SAYURAN PORTABEL TIPE VAKUM UNTUK PEMBIBITAN PADA TALAM SEMAI
}

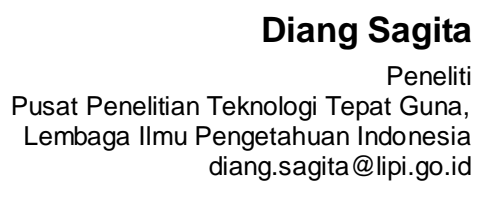

Diang Sagita

Peneliti

Pusat Penelitian Teknologi Tepat Guna, diang.sagita@lipi.go.id
In Indonesia, vegetable seeding technique in nursery plug trays still uses manual mechanism. Furthermore, the small size of vegetable seeds makes it difficult to allocate the seeds evenly (1 seed per planting hole). This study aims to design and construct a portable vegetable seeder with a vacuum-type mechanism for nursery needs in plug trays. The methods used in this study were: 1) preliminary test of seed characteristics, 2) functional analysis of the design, 3) structural analysis of the design using CAD, 4) fabricating a prototype, and 5) performance test of the seeder prototype. Seed characteristic used as reference analysis was mustard green seeds. The nursery plug tray used was TS-128L tray (128 planting holes). The results show that the suction requirement of the seeder was 23.119 Pa and the seed suction holes diameter was $1 \mathrm{~mm}$ with a cone angle of $120^{\circ}$. The overall dimensions of the machine are $585 \times$ $430 \times 105 \mathrm{~mm}$ with $5.26 \mathrm{~kg}$ of weight. The suction power uses $220 \mathrm{~V}$ AC electric blower with 1.5 A of electric current, 2.5 inches of inlet hole, $3600 \mathrm{rpm}$ of blower rotation and $412.02 \mathrm{~Pa}$ of suction power (bigger than the suction requirement of the seeder). The performance test results of seeder using mustard green seeds have been able to achieve the uniformity level of $93.75 \%$ (1 seed per planting hole), germination percentage of $95.05 \%$ and seeding capacity of 102 trays/hour.

Keywords: Nursery Plug Tray, Vacuum Type, Vegetable Seeder, Vegetable Seeds.

\section{PENDAHULUAN}

Kegiatan penyemaian benih sayuran pada talam semai untuk keperluan pembibitan masih dilakukan secara manual dengan cara menaburan benih ke atas media tanam yang sudah disiapkan atau dengan memasukan satu persatu benih pada lubang talam semai. Umumnya, talam semai diisi dengan substrat tanpa tanah yang terdiri dari cocopeat dan vermiculite. Kegiatan pembibitan menggunakan talam semai (tray) adalah salah satu teknik budidaya untuk memaksimalkan perkecambahan sebelum dipindahkan ke lahan terbuka/kebun [1].

Teknik pembibitan pada talam semai berkembang dengan cepat karena lebih menguntungkan bagi petani dan pengusaha. Pembibitan umumnya dilakukan untuk benih-benih yang berukuran kecil dan berharga relatif mahal seperti sawi, kubis, selada, cabai, tomat, dan sebagainya (kecuali bayam karena bayam umumnya ditanam langsung) [2]. Namun demikian, aktivitas pembibitan pada talam semai merupakan kegiatan yang paling banyak membutuhkan tenaga kerja. Diperlukan sekitar delapan jam kerja untuk menabur 100 talam semai, sehingga hal ini menjadi kendala apabila kurangnya tenaga kerja [1]. Selain itu, kendala lain pembibitan sayuran adalah ukuran benih yang sangat kecil. Akibatnya adalah tingkat keseragaman penjatahan benih menjadi kurang seragam ( $>1$ benih per lubang tanam). Keseragaman jumlah benih merupakan salah satu faktor penting yang harus dipenuhi oleh penjatah benih [3].

Salah satu solusi penanganan permasalahan tersebut adalah dengan membuat sebuah desain mesin penyemai benih sayuran dengan menggunakan mekanisme vakum, bersifat portabel dan praktis (mudah dibawa dan dipindahkan). Mekanisme vakum dipilih karena memiliki keunggulan yaitu kualitas penanaman lebih baik, lebih akurat/presisi, tingkat kerusakan benih rendah, kontrol dan perawatan mudah [4], [5]. Beberapa mesin penyemai yang sudah banyak dikembangkan di dalam dan luar negeri adalah untuk benih 
berukuran besar seperti padi, jagung, kedelai [5]-[8]. Adapun untuk benih kecil telah dikembangkan di luar negeri seperti yang dikembangkan oleh Gaikwad dan Sirohi [1], namun desain mesinnya cukup rumit dan masih kurang praktis dan portabel sehingga perlu dibuat desain yang lebih praktis, mudah dibawa dan dioperasikan oleh pengguna. Selain itu mesin-mesin yang sudah ada tersebut masih harus diimpor dari luar negeri apabila ingin diterapkan di Indonesia yang mengakibatkan harganya menjadi tinggi. Penelitian ini bertujuan untuk mendesain dan mengkonstruksi mesin penyemai benih sayuran yang portabel dan menggunakan mekanisme vakum untuk keperluan pembibitan pada talam semai. Mesin tersebut diharapkan dapat berdampak pada peningkatan kecepatan penyemaian benih sayuran, dan meningkatkan kualitas tanaman khususnya penjatahan yang seragam (1 benih/lubang tanam).

\section{METODE DAN BAHAN}

Penelitian ini dilakukan dalam beberapa tahapan yaitu: 1) pengujian pendahuluan terhadap karakteristik benih untuk keperluan desain, 2) analisis rancangan fungsional, 3) analisis rancangan struktural menggunakan aplikasi CAD, 4) pembuatan prototipe dan 5) pengujian kinerja mesin. Flowchart dari tahapan penelitian yang dilakukan disajikan pada Gambar 1. Karakteristik benih yang digunakan sebagai acuan analisis adalah benih caisim (Brassica rapa L.) dan talam yang digunakan adalah talam dengan tipe TS-128L (jumlah lubang 128).

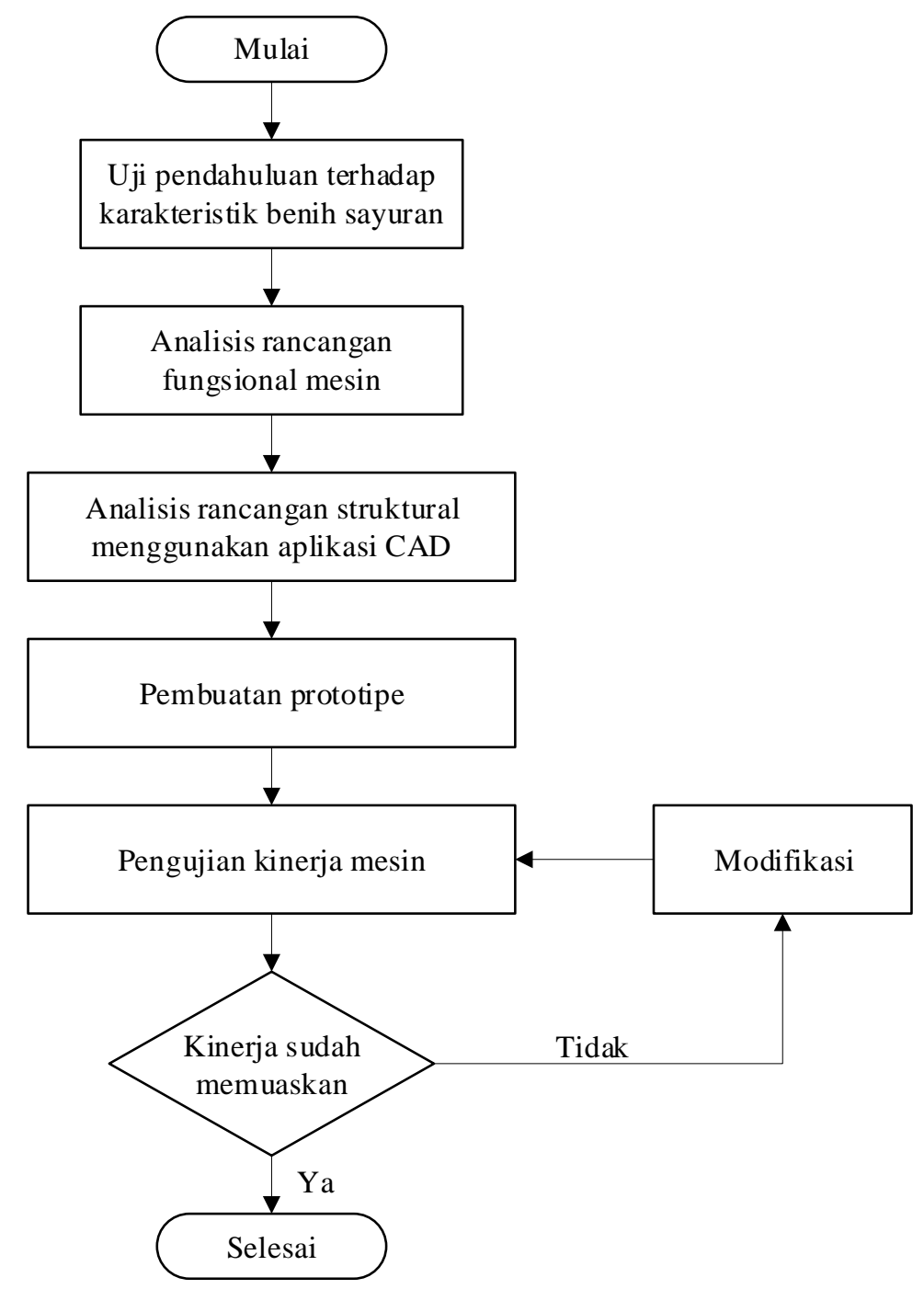

Gambar 1. Flowchart tahapan penelitian yang dilakukan.

Pengukuran karakteristik bahan dilakukan untuk mengetahui beberapa karakter dari bahan yang berguna untuk analisis perancangan mesin penyemai. Alat ukur yang digunakan yaitu digital caliper dengan ketelitian $0.01 \mathrm{~mm}$, timbangan digital dengan ketelitian $0.01 \mathrm{~g}$ dan penggaris dengan ketelitian $1 \mathrm{~mm}$. Benih 
yang digunakan untuk pengukuran adalah benih caisim (Brassica rapa L.) yang dijual secara umum di toko bibit/pertanian. Beberapa karakteristik benih yang diperlukan untuk perancangan desain mesin penyemai antara lain diameter geometri benih $\left(D_{g}\right)$ sebagai acuan penentuan diameter lubang hisap benih pada metering device, bulk density $\left(\rho_{b}\right)$ sebagai acuan perhitungan volume hopper benih, sudut curah $(\theta)$ sebagai acuan untuk merancang kemiringan tempat benih dan massa satu benih caisim $\left(m_{p}\right)$ sebagai parameter perhitungan kebutuhan tekanan hisap minimum. Diameter geometri benih dihitung menggunakan Persamaan 1, bulk density dihitung dengan Persamsaan 2, Sudut curah dihitung dengan Persamaan 3 (sketsa pengukuran pada Gambar 2) dan massa satu benih caisim dihitung dengan Persamaan 4. Persamaan-persamaan tersebut telah banyak digunakan untuk pengukuran karakteristik benih sebagaimana yang dilakukan oleh Bakhtiari dan Ahmad [9] serta Sagita [5]. Pengukuran diameter benih dilakukan pada 100 sampel benih, massa 1 benih, bulk density, sudut curah masing masing diukur tiga kali ulangan.

$$
\begin{aligned}
& D_{g}=\left(l_{k} \times w_{k} \times t_{k}\right)^{1 / 3} \\
& \rho_{b}=\frac{m_{b}}{v_{b}} \\
& \theta=\tan ^{-1}\left(\frac{H}{R}\right) \\
& m_{p}=\frac{m_{1 g}}{j_{b}}
\end{aligned}
$$

Dalam hal ini, $l_{k}$ adalah panjang $(\mathrm{mm}), w_{k}$ adalah lebar $(\mathrm{mm}), t_{k}$ adalah tebal $(\mathrm{mm}), m_{b}$ adalah massa benih pada wadah $(\mathrm{g}), v_{b}$ adalah volume benih dalam wadah $\left(\mathrm{mm}^{3}\right) . m_{l g}$ adalah massa sejumlah benih $(1 \mathrm{gram}), J_{b}$ adalah jumlah benih dalam massa 1 gram.

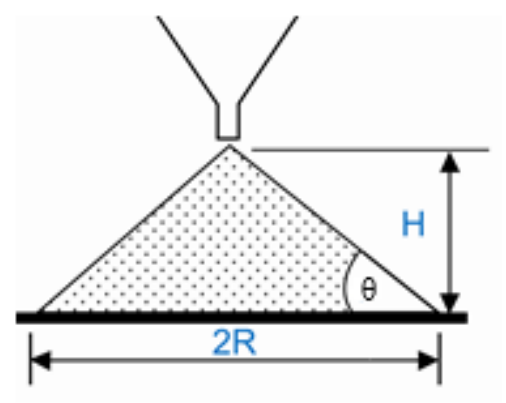

Gambar 2. Sketsa pengukuran sudut curah benih.

Analisis rancangan fungsional dan struktural merupakan analisis yang umum digunakan untuk rancang bangun suatu alat/mesin [5], [10]. Analisis fungsional mesin penyemai ditentukan berdasarkan fungsi apa saja yang harus ada pada mesin penyemai, sementara analisis struktural merupakan hasil representasi dari fungsi-fungsi yang dibutuhkan sehingga menjadi suatu gambaran utuh dari mesin yang dibuat. Pada analisis struktural, digunakan bantuan aplikasi Computer Aided Design (CAD) sehingga dapat dihasilkan langsung gambar teknik lengkap dengan ukuran mesin yang dibuat. Setelah desain terbentuk, dilanjutkan dengan pembuatan prototipe mesin. Prototipe yang sudah jadi kemudian diuji kinerjanya. Adapun parameter pengujian yang diukur antara lain: tekanan hisap yang dihasilkan, persentase penjatahan 1 benih/lubang tanam dan kapasitas lapang mesin. Tekanan hisap diukur menggunakan manometer air sehingga diperoleh data beda ketinggian air $(\mathrm{mm})$, kemudian tekanan dalam satuan Pa dihitung menggunakan Persamaan 5. Pengukuran dilakukan sebanyak 3 kali.

$$
P=\rho \times g \times h
$$

Dalam hal ini, $P$ adalah tekanan total $(\mathrm{Pa}), \rho$ adalah masa jenis fluida $\left(\mathrm{kg} / \mathrm{m}^{3}\right), g$ adalah gravitasi $\left(\mathrm{m} / \mathrm{s}^{2}\right)$ dan $h$ adalah beda ketinggian air $(\mathrm{m})$.

Persentase penjatahan dilakukan dengan cara menghitung jumlah benih yang jatuh pada tiap lubang tanam pada talam semai dengan kriteria: 1) nol benih, 2) satu benih, 3) dua benih dan 4) lebih dari dua benih pada tiap lubang tanam, kemudian masing-masing kriteria dihitung persentasenya. Pengujian dilakukan sebanyak 3 ulangan. Sementara itu, kapasitas lapang mesin diukur berdasarkan waktu penyemaian tiap talam 
semai dan mengujinya sebanyak 3 kali ulangan sehingga akan didapatkan rata-rata kapasitas lapangan penyemaian menggunakan mesin ini. Cara perhitungan disajikan pada Persamaan 6.

$$
K_{L}=\frac{J_{s}}{t}
$$

Dalam hal ini, $K_{L}$ adalah kapasitas lapang mesin (talam semai/jam), $J_{s}$ adalah jumlah talam semai yang dijatah (dalam hal ini 1 talam semai) dan $t$ adalah waktu untuk menyemai 1 talam semai (jam).

\section{HASIL DAN DISKUSI}

\subsection{Karakteristik Benih Caisim}

Menurut Cahyono [11], benih caisim berbentuk bulat, berukuran kecil, permukaanya licin mengkilap, agak keras dan berwarna coklat kehitaman. Karakteristik benih caisim hasil pengukuran disajikan pada Tabel 1. Berdasarkan hasil pengukuran diperoleh besarnya dimensi geometri benih caisim rata-rata adalah $1.39 \mathrm{~mm}$, bulk density rata-rata sebesar $0.6 \mathrm{~g} / \mathrm{cm}^{3}$, sudut curah $16.66^{\circ}$ dan massa satu benih caisim sebesar $3.7 \mathrm{mg}$. Data-data tersebut kemudian digunakan untuk menganalisis dan merancang mesin penyemai sehingga diperoleh hasil desain yang optimal.

Tabel 1. Hasil pengukuran karakteristik benih caisim untuk keperluan analisis.

\begin{tabular}{l|l|l}
\hline KARAKTERISTIK BENIH & NILAI & SATUAN \\
\hline Dimensi geometri $\left(D_{g}\right)$ & $1.39 \pm 0.14$ & $\mathrm{~mm}$ \\
\hline Bulk density $\left(\rho_{b}\right)$ & $0.6 \pm 0.0$ & $\mathrm{~g} / \mathrm{cm}^{3}$ \\
\hline Sudut curah $(\theta)$ & $16.66 \pm 0.87$ & $\mathrm{o}$ \\
\hline Massa 1 benih $\left(m_{p}\right)$ & $3.7 \pm 0.2$ & $\mathrm{mg}$ \\
\hline
\end{tabular}

\subsection{Rancangan Fungsional}

Secara fungsional, mesin penyemai benih tipe vakum ini berfungsi untuk menyemai benih secara cepat dan tepat pada talam semai serta dapat menjatah benih dengan jumlah yang seragam yaitu satu benih per lubang tanam. Rancangan fungsional dapat dilihat pada Tabel 2. Adapun dari segi kriteria desainnya, mesin penyemai benih tipe vakum dirancang memiliki kriteria sebagai berikut:

1. Mesin penyemai benih menggunakan tipe vakum

2. Unit penghisap yang digunakan adalah blower elektrik dengan sumber listrik AC $220 \mathrm{~V}$

3. Unit penghisap harus mampu menghisap seluruh benih pada setiap lubang hisap

4. Mesin penyemai harus mampu menjatah satu benih per lubang tanam pada talam semai

5. Mesin penyemai bekerja pada talam semai tipe TS-128L (jumlah lubang 128)

6. Benih harus terletak pada tepat pada tiap lubang tanam pada talam semai

7. Kapasitas penyemaian mesin harus lebih tinggi dibandingkan penyemaian secara manual

Tabel 2. Rancangan fngsional mesin penyemai benih tipe vakum.

\begin{tabular}{lll}
\hline FUNGSI UTAMA & SUB FUNGSI & KOMPONEN \\
\hline & Tempat talam semai & Rangka dari plat besi \\
& Menampung benih & Hopper dari plat besi \\
Menyemai benih sayuran dengan & Menjatah benih & Metering device vakum \\
jumlah yang seragam yaitu 1 benih & Menyalurkan daya hisap dari & Saluran udara (karet) \\
per lubang tanam secara tepat dan & blower ke penjatah benih & \\
akurat pada seluruh lubang tanam & Memposisikan penjatah benih & Mekanisme engsel \\
& ke atas talam semai & \\
\hline
\end{tabular}




\subsection{Rancangan Struktural}

Analisis rancangan struktural dilakukan untuk menentukan bentuk, ukuran/dimensi dan material yang digunakan dari masing-masing komponen alat yang akan didesain. Bagian-bagian mesin yang dirancang mencakup rangka, unit penjatah benih, hopper, vacuum chamber, engsel pada rangka dan unit penghisap (blower) yang digunakan. Sketsa bagian rangka dudukan, unit penjatah benih, penampung benih (hopper), vacuum chamber beserta engsel disajikan pada Gambar 3.

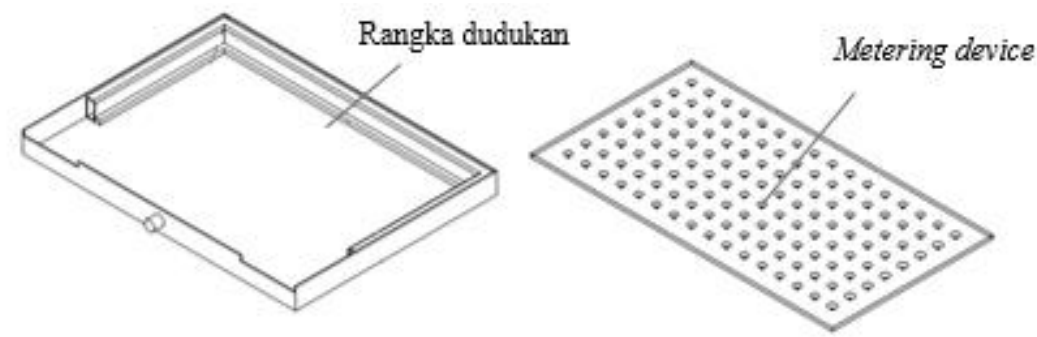

(a)

(b)

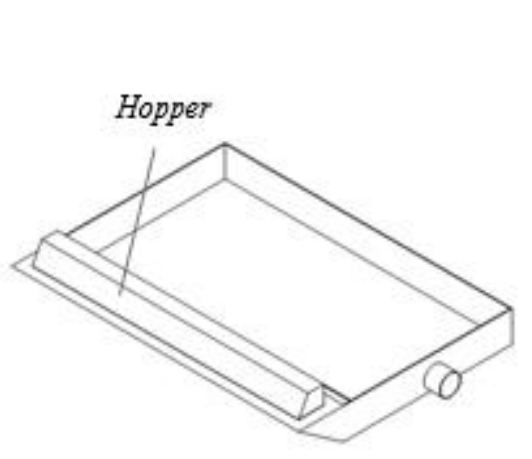

(c)

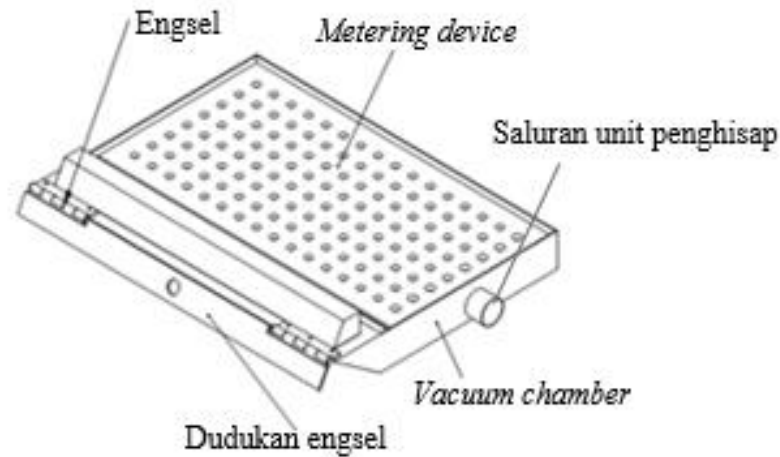

(d)

Gambar 3. Rancangan struktural mesin penyemai (a) rangka dudukan, (b) metering device, (c) hopper, dan (d) engsel pada vacuum chamber.

Rangka utama terbuat dari besi balok $30 \times 20 \mathrm{~mm}$, ketebalan $2 \mathrm{~mm}$ dan plat besi ketebalan $2 \mathrm{~mm}$. rangka dibuat sedemikian rupa agar dapat cocok dengan talam semai yang biasa digunakan. Talam semai ini memiliki 128 lubang (Gambar 4) dengan ukuran panjang dan lebar 540×280 mm, jumlah lubang melebar 8 dan lubang memanjang 16. Bentuk lubang semai kotak dengan jarak antar pusat lubang adalah $34 \times 34 \mathrm{~mm}$. Berdasarkan tipe talam semai tersebut, maka desain mesin penyemai dapat dilihat pada Gambar 5.

Bagian metering device atau penjatah benih yang dirancang adalah menggunakan tipe vacuum. Penjatah terdiri dari plat acrylic $6 \mathrm{~mm}$ dengan lubang hisap berjumlah sesuai dengan lubang tanam pada talam semai. Pada bagian belakang plat penjatah dibuat kondisi vacuum sehingga saat benih melewati lubang hisap tersebut maka benih akan terhisap dan tersangkut pada lubang hisap untuk kemudian penjatah diposisikan agar tepat berada diatas talam semai melalui mekanisme engsel, kemudian blower dimatikan agar benih jatuh ke dalam setiap lubang tanam.

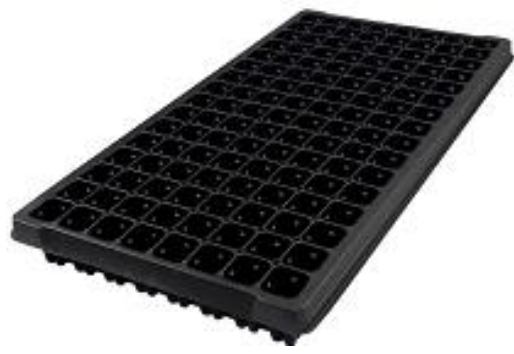

Gambar 4. Talam semai yang digunakan sebagai acuan dimensi mesin. 


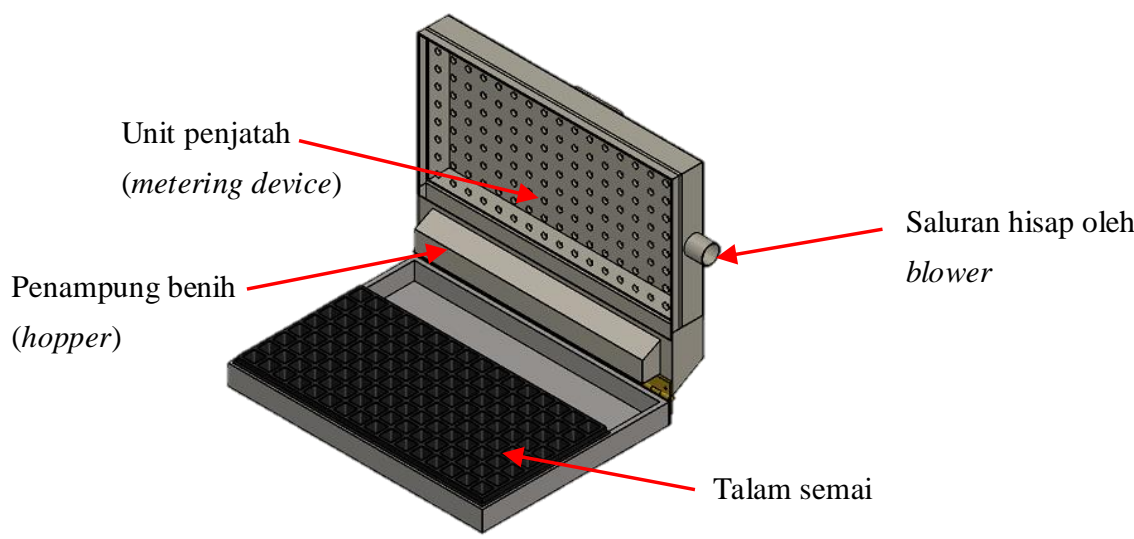

Gambar 5. Desain konseptual mesin penyemai benih sayuran portabel tipe vakum.

Salah satu parameter yang penting untuk dianalisis adalah diameter lubang hisap benih $\left(d_{o}\right)$. Setiap jenis tanaman memiliki ukuran benih yang berbeda sehingga ukuran $d_{o}$ harus disesuaikan dengan ukuran benih tanaman yang digunakan sebagai contoh Yazgi dan Degirmencioglu [12] mengkonfirmasi besarnya dimensi $d_{o}$ optimum untuk benih kapas adalah $3 \mathrm{~mm}$. Berdasarkan penelitian Bakhtiari dan Ahmad [9], diameter lubang hisap benih $\left(d_{o}\right)$ adalah $50 \%$ dari diameter geometri rata-rata benih $\left(D_{g}\right)$ sementara menurut Singh et al. [13] $d_{o} \leq 50 \% D_{g}$. Penampang lubang hisap benih yang dirancang Bakhtiari dan Ahmad [9], [14]

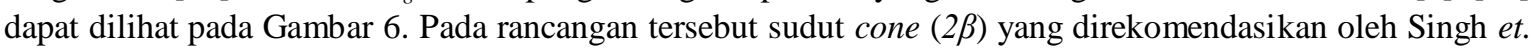
al. [13] dan Bakhtiari [15] adalah sebesar $90^{\circ}, 120^{\circ}$, dan $150^{\circ}$. Diameter geometri benih rata-rata adalah 1.39 $\mathrm{mm}$, maka $d_{o}$ yang dikehendaki adalah $\leq 50 \% D_{g}$ yaitu $1 \mathrm{~mm}$. Kemudian untuk menghitung $D_{o}$ harus mempertimbangkan nilai $b$ yaitu $1 \mathrm{~mm}$, dan sudut $2 \beta$ yang dipilih adalah $120^{\circ}$ sehingga $\beta=60^{\circ}$. Nilai diameter luar $\left(D_{o}\right)$ dihitung dengan Persamaan 7 [9]. Dengan persamaan tersebut diperoleh nilai $D_{o}$ sebesar $4.5 \mathrm{~mm}$.

$$
D_{o}=2 a+d_{o}=2 b \times \tan \beta+d_{o}
$$
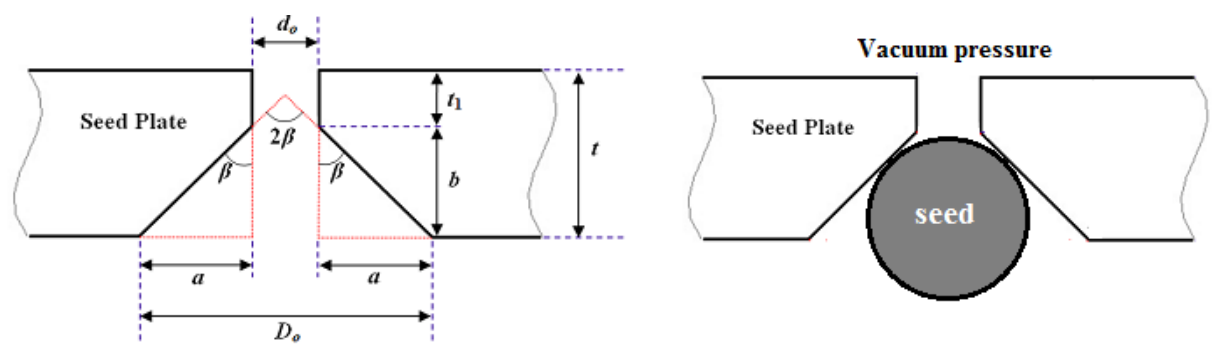

Gambar 6. Rancangan lubang hisap metering device berdasarkan Bakhtiari [15].

Perancangan berikutnya adalah penampung benih (hopper). Hopper berfungsi untuk menampung benih sayuran pada saat penyemaian. Perancangan hopper didasarkan pada target banyaknya talam semai yang ingin disemai tiap satu kali pengisian benih, sehingga perlu dirancang volume hopper sesuai kriteria tersebut. Perancangannya ditentukan berdasarkan Persamaan 8.

$$
V=\frac{J_{t} \times n_{t} \times m_{p}}{\rho_{b}}
$$

Dalam hal ini $V$ adalah volume hopper minimum $\left(\mathrm{cm}^{3}\right), J_{t}$ adalah target jumlah talam semai untuk sekali pengisian, $n_{t}$ adalah jumlah lubang tanam per talam semai (benih/talam semai), $m_{p}$ adalah massa rata-rata benih $(\mathrm{g} / \mathrm{benih})$ dan $\rho_{b}$ adalah bulk density dari benih $\left(\mathrm{g} / \mathrm{cm}^{3}\right)$.

Target jumlah talam semai yang diisi untuk sekali pengisian adalah 200 talam semai, jumlah lubang tanam per talam adalah 128, massa rata-rata benih berdasarkan hasil pengukuran adalah $0.0037 \mathrm{~g}$ dan bulk density benih hasil pengukuran adalah $0.6 \mathrm{~g} / \mathrm{cm}^{3}$. Berdasarkan perhitungan diperoleh nilai volume hopper minimum adalah $157.8 \mathrm{~cm}^{3}$, sehingga desain hopper dibuat lebih besar dari kapasitas minimum tersebut. 
Vacuum chamber merupakan bagian penting dari mesin karena merupakan sebuah ruang yang membuat kondisi vakum sehingga tekanan hisap akan terpusat pada setiap lubang hisap benih. Selain itu, vacuum chamber juga berfungsi sebagai dudukan metering device dan hopper sehingga dimensinya perlu dirancang sesuai kriteria dari metering device dan hopper. Desainnya dapat dilihat pada Gambar 7.

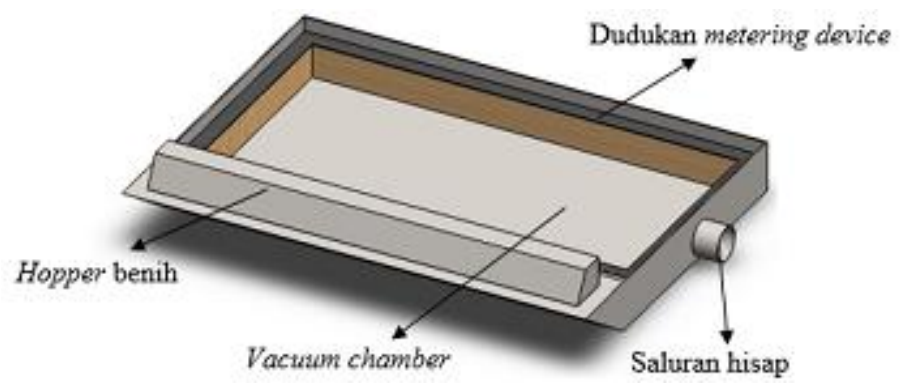

Gambar 7. Desain konseptual vacuum chamber.

Kemudian agar penyebaran benih mudah maka vacuum chamber harus dapat bergerak pada bidang XY sehingga harus mempertimbangkan sudut curah benih agar pada saat dimiringkan benih dapat tergelincir dan tersebar pada metering device. Sudut curah benih caisim berdasarkan hasil pengukuran adalah $16.66^{\circ}$. Sehingga sudut alfa $(\alpha)$ harus lebih besar dari nilai tersebut. Pada saat benih tersebar di permukaan metering device (vacuum chamber digerakkan oleh operator), benih-benih akan tersebar mengisi setiap lubang hisap sejumlah satu benih per lubang karena adanya tekanan hisap pada setiap lubang. Diameter lubang hisap yang telah dirancang sebagaimana Persamaan 7 dan Gambar 6 memungkinkan benih yang tertahan pada lubang hanya berjumlah satu karena setelah satu benih tertahan pada lubang maka lubang menjadi tertutup yang mengakibatkan benih lain tidak akan terhisap. Gambar 8 menunjukkan konsep penggunaan mesin ketika dimiringkan. Selain itu, untuk mempermudah penyebaran benih pada metering device, vacuum chamber juga dibuat agar dapat bergerak pada sumbu YZ, sehingga digunakan poros pada pusat dudukan engsel seperti pada Gambar 9.
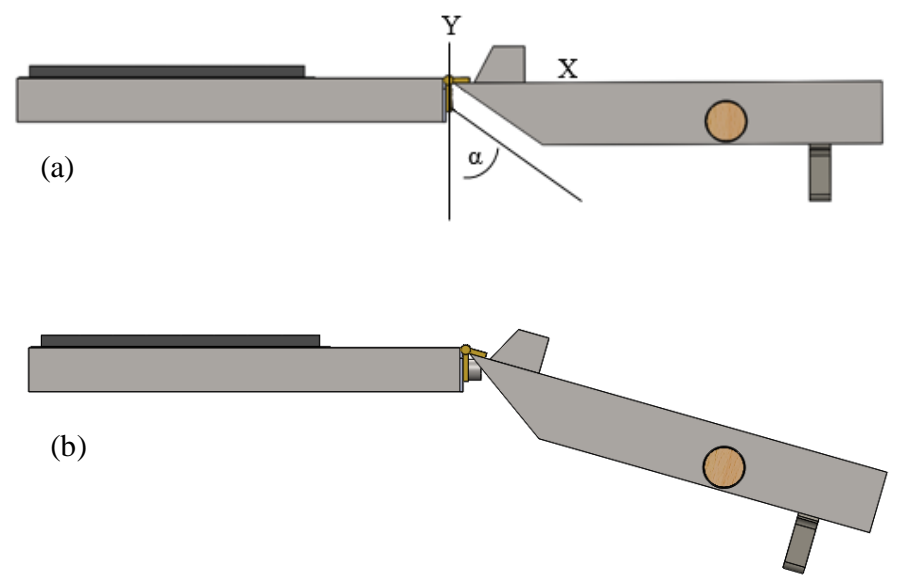

Gambar 8. Mekanisme engsel pergerakan unit penjatah pada bidang XY (a) posisi horizontal, (b) posisi dimiringkan.

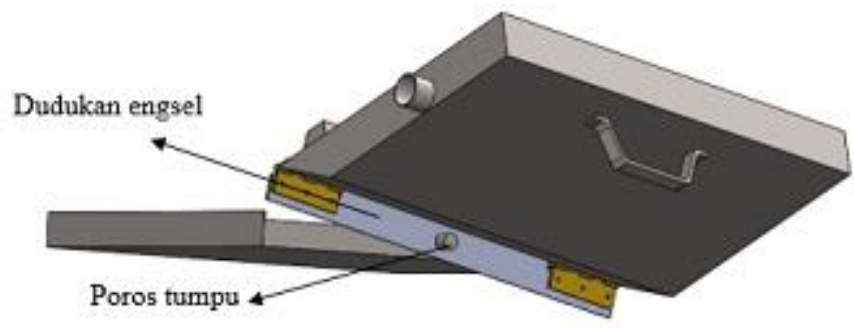

Gambar 9. Mekanisme pergerakan unit penjatah pada bidang YZ. 
Setelah setiap bagian selesai didesain dan analisis, maka untuk lebih menjelaskan struktur setiap komponen dan susunan dari mesin penyemai, disajikan Gambar 10 yang memperlihatkan setiap komponen dari mesin.

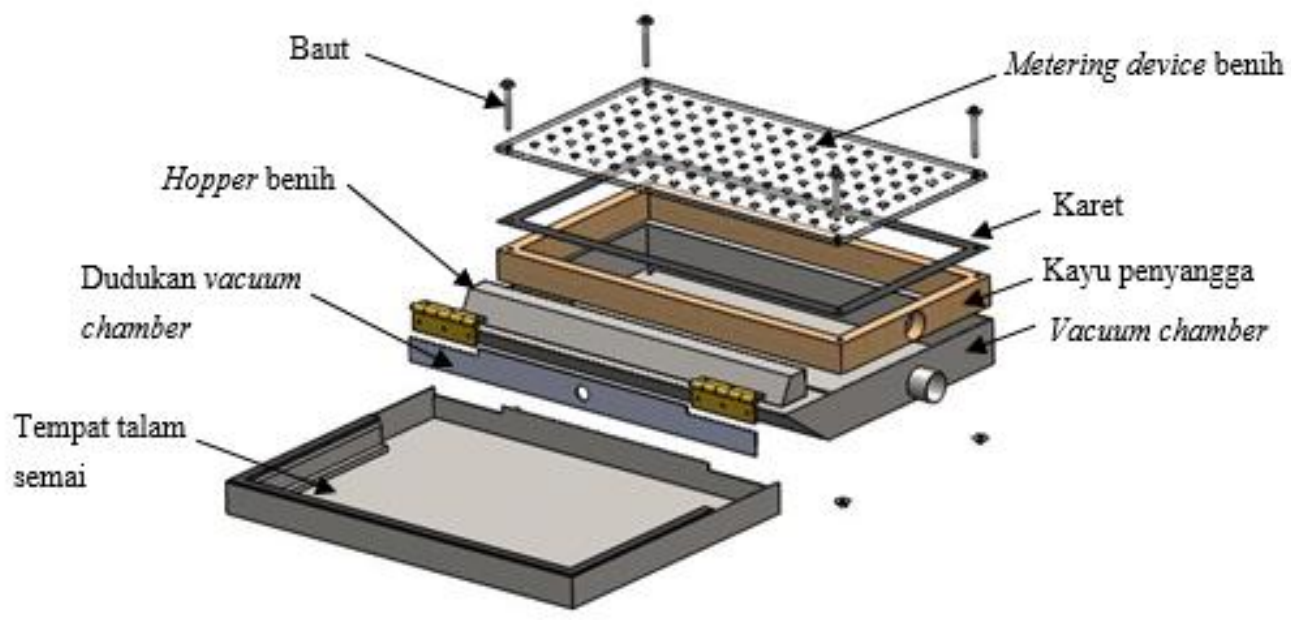

Gambar 10. Rangkaian komponen mesin penyemai benih portabel tipe vakum.

Selanjutnya bagian sisi hisap blower digunakan untuk menciptakan kondisi vacuum sehingga benih dapat terhisap. Bagian penting blower terdiri dari impeller dan rumah blower. Impeller yang berputar akan menurunkan tekanan lokal sehingga dengan perbedaan tekanan, udara akan mengalir menuju pusat impeller untuk selanjutnya dialirkan keluar dengan gaya sentrifugal sudu-sudu blower. Rumah blower berfungsi sebagai boundary dari sistem aliran agar sistem tersebut dapat memanipulasi kondisi udara seperti yang diinginkan. Blower yang digunakan pada mesin penyemai ini merupakan blower elektrik yang sudah tersedia di pasaran, namun perlu dilakukan analisis kebutuhan hisapan dan ukuran blower yang sesuai dengan kapasitas mesin yang dibuat. Jenis blower yang digunakan dapat dilihat pada Gambar 11.

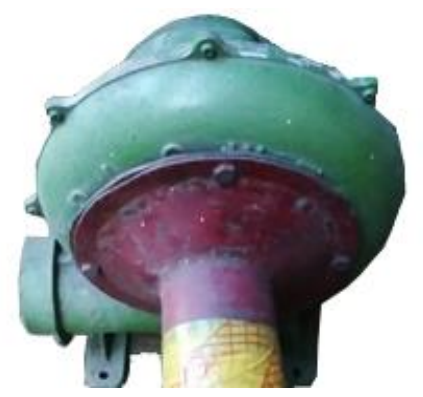

Gambar 11. Jenis blower elektrik yang digunakan (tipe 2.5" lubang inlet, $220 \mathrm{~V} \mathrm{AC).}$

Blower yang digunakan mengacu pada kebutuhan tekanan hisap yang diperlukan. Penentuan kebutuhan tekanan hisap dapat dilihat pada Persamaan 9 dan 10 [9].

$$
\begin{aligned}
& P_{0}=\frac{F_{d}}{A_{v}}=\frac{m_{p} \times g}{A_{v}} \\
& P_{m}=P_{0}\left[\frac{D_{g}}{d_{o}}\right]
\end{aligned}
$$

Dalam hal ini, $P_{0}$ adalah tekanan untuk melawan gaya gravitasi $(\mathrm{Pa}), P_{m}$ adalah tekanan minimum yang diperlukan $(\mathrm{Pa}), F_{d}$ adalah $\operatorname{drag}$ force $(\mathrm{N}), A_{p}$ adalah luas proyeksi benih $\left(\mathrm{m}^{2}\right), m_{p}$ adalah masa satu benih $(\mathrm{kg})$, g adalah percepatan gravitasi $\left(\mathrm{m} / \mathrm{s}^{2}\right)$ dan $d_{o}$ adalah diameter lubang hisap $(\mathrm{m})$.

Berdasarkan data pengukuran, massa benih caisim adalah $0.0037 \mathrm{~g}$ dan diameter benih rata-rata adalah $1.39 \mathrm{~mm}$, maka $A_{p}$ dapat dihitung dengan rumus luas setengah permukaan bola sehingga didapatkan nilai $A_{p}$ sebesar $3.03 \mathrm{~mm}^{2}$. Kemudian didapat nilai $P_{o}$ sebesar $11.98 \mathrm{~Pa}$ dan $P_{m}$ sebesar 23.119 Pa. Pada 
penerapannya digunakan blower yang tersedia dipasaran yaitu blower elektrik dengan spesifikasi yaitu menggunakan listrik AC $220 \mathrm{~V}$ dan arus $1.5 \mathrm{~A}$, lubang inlet 2.5 inchi, putaran $3600 \mathrm{rpm}$. Blower tersebut belum diketahui besar tekanan hisapnya sehingga dilakukan pengukuran terhadap tekanan yang dihasilkannya. Blower tersebut diharapkan dapat melebihi tekanan vakum minimum yang dibutuhkan agar mesin penyemai dapat berfungsi sesuai yang diharapkan.

\subsection{Konstruksi Mesin Penyemai Portabel Tipe Vakum}

Prototipe mesin penyemai benih caisim tipe vakum telah berhasil dibuat. Mesin ini mampu untuk menyemai benih caisim sekaligus pada talam semai (tray) dengan jumlah lubang tanam 128. Konstruksi prototipe ini terdiri dari rangka utama, vacuum chamber, hopper, metering device, saluran hisap dan blower penghisap. Konstruksi prototipe dapat dilihat pada Gambar 12 dan Gambar 13. Dimensi keseluruhan mesin adalah $585 \times 430 \times 105 \mathrm{~mm}$ dengan bobot sebesar $5.26 \mathrm{~kg}$ sehingga mudah untuk dibawa dan dipindahkan oleh satu orang dewasa (portabel).

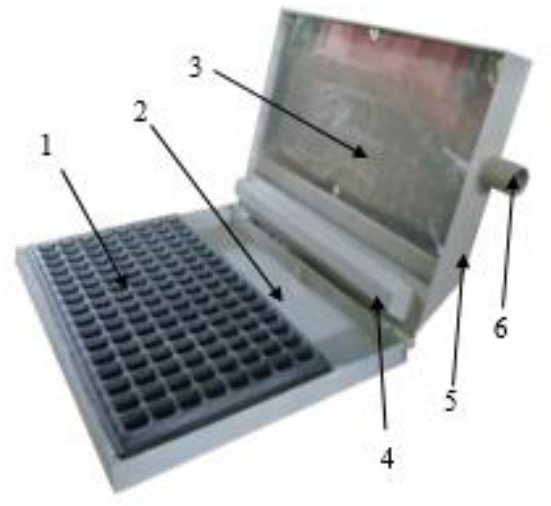

Keterangan:

1. Tray semai (128 lubang)

2. Rangka dudukan tray

3. Metering device

4. Hopper

5. Vacuum chamber

6. Saluran hisap

Gambar 12. Konstruksi prototipe mesin penyemai portabel tipe vakum.

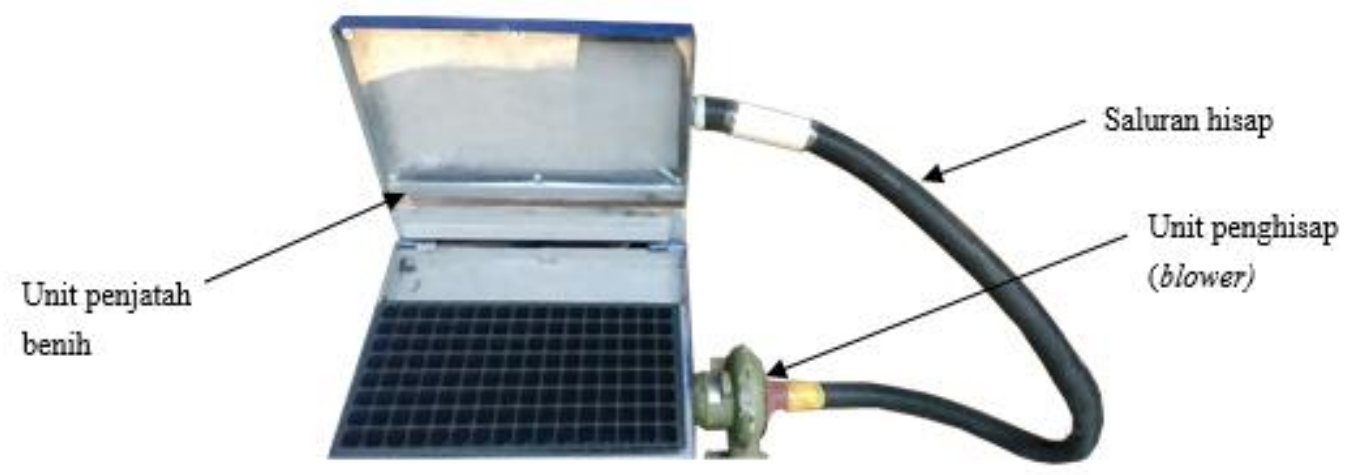

Gambar 13. Konstruksi prototipe mesin penyemai portabel tipe vakum.

\subsection{Kinerja Mesin Penyemai Portabel Tipe Vakum}

Parameter kinerja penjatahan yang pertama adalah keseragaman penjatahan benih yang diuji sebanyak 3 ulangan. Persentase penjatahan 1 benih per lubang menggunakan mesin penyemai mampu mencapai persentase yang tinggi yaitu $93.75 \%$. Penjatahan 2 benih dan $>2$ benih per lubang masing-masing $3.13 \%$ dan $1.56 \%$, sementara itu persentase lubang tidak terisi ( 0 benih) hanya $1.56 \%$. Grafik persentase penjatahan benih disajikan pada Gambar 14. Dalam hal ini, penyemaian menggunakan mesin ini dapat dikatakan berhasil karena mampu menjatah lebih dari $93 \%$ benih dengan jumlah 1 benih/lubang. Pada saat pengujian tersebut, besarnya tekanan hisap yang dihasilkan oleh blower adalah $412.02 \mathrm{~Pa}$. Nilai tersebut jauh melebihi kebutuhan hisap minimum benih caisim sehingga metering device benih mampu menghisap benih dan menahannya pada metering device dengan kuat.

Parameter uji berikutnya adalah kapasitas lapang mesin yang merupakan kemampuan alat/mesin untuk menyelesaikan pekerjaan selama waktu tertentu. Kapasitas lapang mesin diukur berdasarkan waktu penyemaian tiap talam semai. Rata-rata waktu $(t)$ untuk penyamaian satu talam semai dengan mesin adalah 
0.59 menit atau 0.0098 jam sehingga kapasitas kerja mesinnya mencapai 102 talam semai/jam. Sementara menurut Gaikwad dan Sirohi [1], pengerjaan penyemaian secara manual oleh manusia, untuk menyemai 100 talam semai dapat menghabiskan waktu sekitar 8 jam. Artinya penggunaan mesin ini sudah mampu meningkatkan kapasitas penyemaian sampai 8 kali lipat.

Tingkat keberhasilan penjatahan juga diukur berdasarkan persentase perkecambahan benih. Pengamatan perkecambahan dilakukan mulai dari 1 hari setelah tanam (HST) hingga 3 HST. Pada hari ke-1 belum ada kecambah yang tumbuh karena kondisi media tanam tidak cukup lembab (benih tidak dapat menyerap air) sehingga dilakukan penyiraman dan penutupan dengan plastik kedap udara agar kondisi media tanam menjadi lembab. Pada hari ke-2, kecambah mulai tumbuh sebanyak $94.01 \%$ dari total lubang benih, kemudian pada hari ke-3 persentase kecambah meningkat menjadi 95.05\%. Sementara itu, 4.95\% lubang tanam yang tidak ditumbuhi kecambah terjadi karena tidak adanya benih di dalam lubang tanam ( 0 benih) dan juga faktor internal benih yang spesifikasi daya tumbuhnya memang tidak sampai 100\%. Hasil pertumbuhan kecambah dapat dilihat pada Gambar 15. Berdasakan hasil tersebut dapat diketahui bahwa penggunaan mesin penyemai tipe vakum telah terbukti sebagaimana yang disampaikan Ozmerzi et al. [4] bahwa berbeda dengan alat penyemai tipe mekanis yang memungkinkan gesekan dan benturan, penggunaan tipe vakum yang memanfaatkan hisapan udara tidak merusak benih yang disemai sehingga kualitas perkecambahan sangat baik.

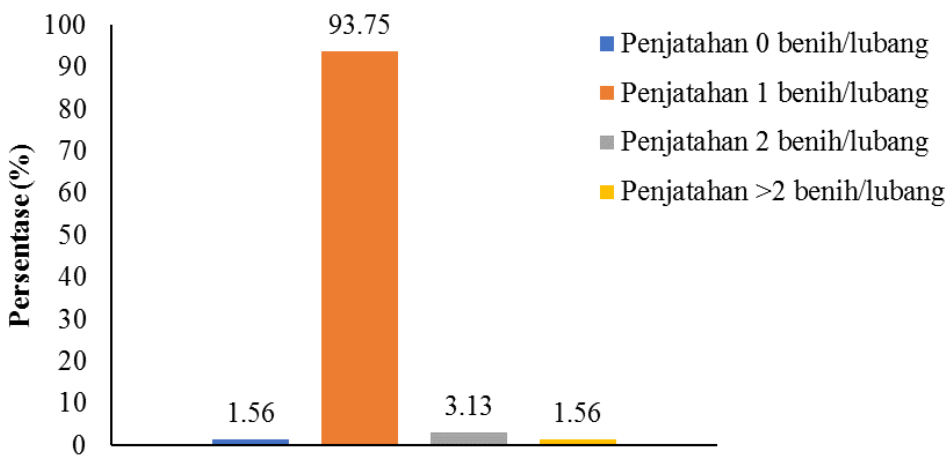

Gambar 14. Rata-rata persentase penjatahan benih menggunakan mesin penyamemai.

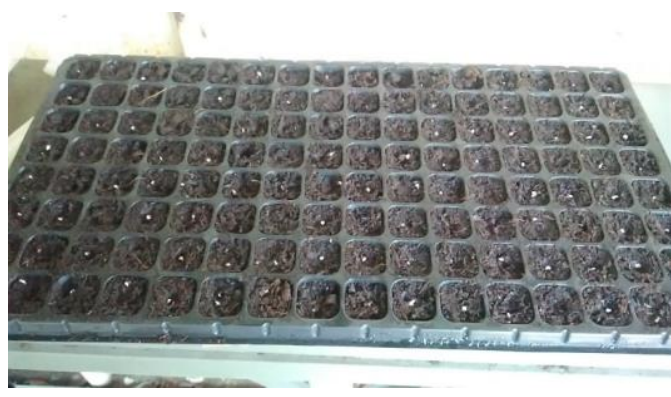

(a)

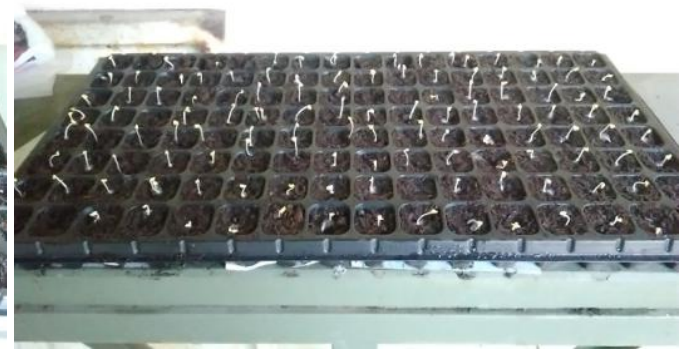

(b)

Gambar 15. Pertumbuhan kecambah caisim (a) hari ke-2, (b) hari ke-3.

\section{KESIMPULAN}

Desain mesin penyemai benih sayuran portabel tipe vakum memiliki spesifikasi yaitu kebutuhan hisapan mesin penyemai sebesar $23.119 \mathrm{~Pa}$, diameter lubang hisap sebesar $1 \mathrm{~mm}$ dengan cone angle $120^{\circ}$. Dimensi keseluruhan mesin adalah $585 \times 430 \times 105 \mathrm{~mm}$ dengan bobot sebesar $5.26 \mathrm{~kg}$ sehingga mudah untuk dibawa dan dipindahkan oleh satu orang dewasa. Tenaga hisap mesin menggunakan blower elektrik dengan spesifikasi menggunakan tegangan $220 \mathrm{~V} \mathrm{AC}$, arus listrik $1.5 \mathrm{~A}$, lubang inlet 2.5 inchi, putaran $3600 \mathrm{rpm}$ dan memiliki tenaga hisap sebesar 412.02 Pa sehingga telah memenuhi kebutuhan hisap mesin penyemai. Hasil pengujian penjatahan menggunakan benih caisim mampu mencapai tingkat keseragaman 93.75\% (1 benih per lubang tanam) dan persentase perkecambahan mencapai $95.05 \%$ pada hari ke-3 setelah tanam. Kapasitas penyemaian mesin sebesar 102 talam semai/jam. 


\section{DAFTAR PUSTAKA}

[1] B. B. A. GAIKWAD and N. P. S. SIROHI. 2008. 'Design of a low-cost pneumatic seeder for nursery plug trays', Biosyst. Eng., Vol. 99, pp. 322-329,

[2] BPTP SULSEL. 2019. 'Budidaya sayuran di pekarangan', [Online]. Available: http://sulsel.litbang.pertanian.go.id/ind/index.php/publikasi/panduan-petunjuk-teknis-brosur/132budidaya-sayuran-di-lahan-pekarangan. [Accessed: 12-Jun-2019].

[3] A. K. SRIVAStaVA, C. E. GOERING, R. P. ROHRBACH, and D. R. BUCKMASTER. 2006. Engineering Principles of Agricultural Machines, $2^{\text {nd }}$ edition. Michigan: American Society of Agricultural and Biological Engineers.

[4] A. OZMERZI, D. KARAYEL, and M. TOPAKCI. 2002. 'Effect of sowing depth on precision seeder uniformity', Biosyst. Eng., vol. 82, no. 2, pp. 227-230.

[5] D. SAGITA. 2018. 'Pengembangan unit penanam benih kedelai tipe vakum dan pemupuk bertenaga traktor tangan', Institut Pertanian Bogor.

[6] D. KARAYEL. 2009. 'Performance of a modified precision vacuum seeder for no-till sowing of maize and soybean', Soil \{\&\} Tillage Res., vol. 104, no. 2009, pp. 121-125.

[7] I. HOSSAIN, R. J. ESDAILE, R. BELL, E. HAQUE, and C. JOHANSEN. 2009. 'Development of low cost two whell tractor operated no-till seeder for better establishment of uppland crop', Eco-friendly Agric. J., Vol. 2, No. 11, pp. 915-919.

[8] W. HERMAWAN, T. MANDANG, A. SUTEJO, and L. SAULIA. 2016. 'Design and performance of vacuum type seed metering device for precision soybean planter'. International Symposium on Agricultural and Biosystem Engineering.

[9] M. R. BAKHTIARI and D. AHMAD. 2015. 'Determining physical and aerodynamic properties of garlic to design and develop of a pneumatic garlic clove metering system', AgricEngInt CIGR J., Vol. 17, No. 1, pp. 59-67.

[10] W. SUGANDI, A. YUSUF, and A. THORIQ. 2017. 'Rancang bangun mesin pengiris Talas Semir', Jurnal Rekayasa Mesin, Vol. 8, No. 2, pp. 67-74.

[11] B. CAHYONO. 2003.Teknik dan Strategi Budi Daya Sawi Hijau (Pai-Tsai). Yogyakarta: Yayasan Pustaka Nusantara.

[12] A. YAZGI and A. DEGIRMENCIOGLU. 2007. 'Optimisation of the seed spacing uniformity performance of a vacuum-type precision seeder using response surface methodology', Biosyst. Eng., Vol. 97, pp. 347-356.

[13] R. C. SINGH, G. SINGH, and D. C. SARASWAT. 2005. 'Optimisation of design and operational parameters of a pneumatic seed metering device for planting cottonseeds', Biosyst. Eng., Vol. 92, No. 4, pp. 429-438.

[14] M. R. BAKHTIARI and D. AHMAD. 2017. 'Design of a vacuum seed metering system for kenaf planting', Agric. Eng. Int. CIGR J., Vol. 19, No. 3, pp. 23-31.

[15] M. R. BAKHTIARI. 2012. 'Design, development and evaluation of a kenaf pneumatic seeding machine', Universiri Putra Malaysia. 